

\section{FIMAL REPORT}

Lawrence Livermore Laboratory

Subcontract 8273105

by

C. F. Hooper, II.

Professor of Physics

Principal Investigator
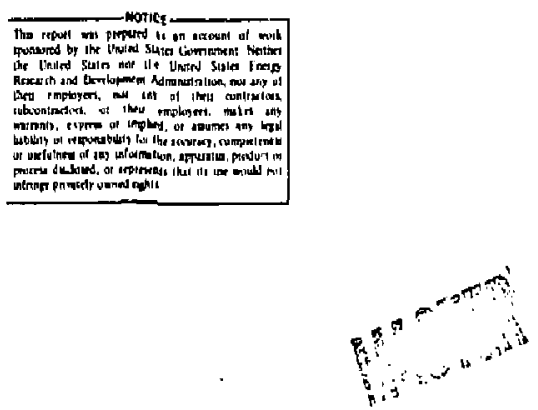


\section{Introduction}

This is the final report of work done under Lawrence Livermore Laboratory subcontract No. 8273105. As such it covers sork alteady reported in the form of manuscript entitled Stark Broadening in Hat Dense Laser-Produced Plasmes, as well as that accomplished subsequently. A slightly revised version of that manuscript Is attached as Appendix A; the paper itself is scheduled to appear in the October issue of Physical Revieu A.

There are 3 topics of primary importance in this report: (1) The calculation of electric-microfield-distribution functions for plasmas having ions and electrons at different kinetic temperatures, (2) The calculation of electric nicroffeld distributions for one-temperature plasuas having two species of ions present in varying ratios, (3) The extension of the line-shape (profile) calculation to higher-seties (Lyman) tiembers.

In addition, brief mention will be made of 2 other problems: (4) The calculation of electric micrafjeld distributions for very dense plasmas, and (5) The derivacion of a new line-broadening theory appropriate for plasmas in which the component patticles are strongly coupled and in which the electrons are at least partially degenerate.

\section{Technical kesults}

(1) The first two-temperature mictofield calculations have just been completed. Figures I through 4 show the results for two representative situations. Each of the graphs is labelerd with the quancitjes $a_{2}, \chi, Z_{1}, R$, and $T_{F}$. The quanticy a is related to the piasula parameter, $\Gamma$ :

$$
\text { Where, } \begin{aligned}
\Gamma & =\frac{a^{2}}{3}, \\
\Gamma & \equiv \frac{\mathrm{e}^{2 / r_{0}}}{\mathrm{kT}} \\
r_{0} & =\left(3 / 4 \pi n_{\mathrm{e}}\right)^{1 / 3}:
\end{aligned}
$$


$n_{e}$ is the electron dersity, $X$ gives the net radiator charge and $z_{1}$ is the charge of the perturbing ion. $R$ is equal to zero in all these figures which implies that there is only one type of ion perturber (of charge $2_{1}$ ), $T_{R}$ is the tatio of electron to ion kinctic temperatures. Figures 1 and 2 refer co the field distribution at an argon XVIII ion in a fully stripped deuteum or hydrugen plasma. AS $T_{R}$ increases from 0.25 to 4,00 , the distribution becomes more sharply peaked and shif ts to smaller ficld strengths. As the plasma becomes more strongly coupled (as a increases) the effect of $T_{R}$ variations is amplified. Figures 3 and 4 are similar to 1 and 2 except that they represent field distributions at an aluminum $X I I I$ radiator that is imersed in a plasta containing only Al XLII tons, The comments made about figures 1 and 2 also apply here. However, by overlaying figures 2 and 4 , it can be seen that the Ai XIII results are doric sensitive to $T_{R}$ variation. This is due to the fact that the correlation betwerin radiator and perturbiag fons $(r, z)$ is greater in this case.

(2) Figures 5 and 6 give the field distributions at an Argon XViI radiator inmersed in a plasma containing both Arger will ions and fully stripped hydregen,

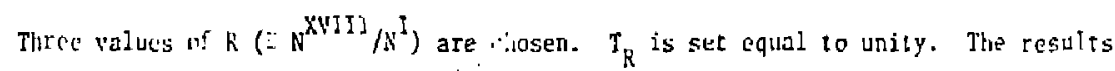
in ligure 5 are for $\underline{a}=0.2$ ar: in figure 6 for $\underline{a}=0.4$. Looking at figure 5 , we see that the viriation in $R$ produces la: $Q^{\mathrm{f}}$ ehanges in the field distribution. Fur:ter-

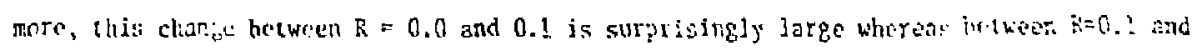

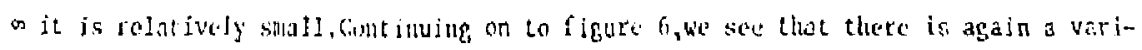
ation in $P(E)$ with R. Altheugh the sensilivity changes som what, wiat is nost strilitus is that the qualitative older of the curves is reversod. This bohavior is we to tie

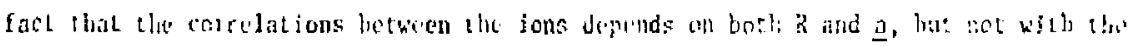

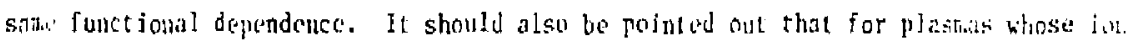

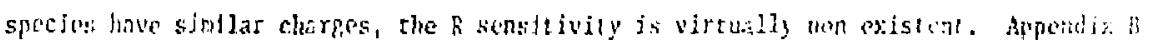

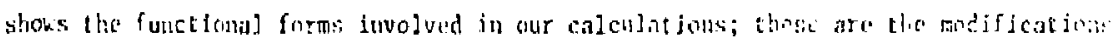

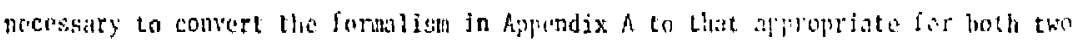


temperatures and two ton-perturber species.

(3) Alchough no numerical calculations have been tade for higher-series numbers, our prograns are being rodified so that we may do so. We expect to produce higherseries-number line shapes within the next wonth or so.

(4) We are currently calculating oficroffeld distributions for strongly coupled plasnas, $\Gamma \gtrsim 1$. To assess the validity of these calculations we are comparing with Monte Carlo rosults being generated by H. E. DeHitt of LLL. Initial results are very promising.

(5) Our efforts to generate a line-broadening theory suttable for strongly coupled degenerate plasmas centers on extending a recently devcloped therry. See the two papers attacted - appendices $C$ and $D$. It is coo early to gauge the final pronise of this technique.

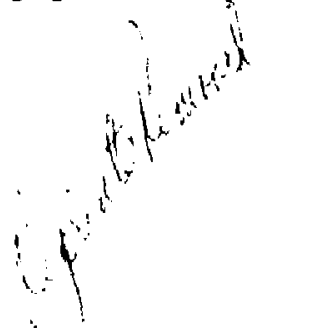


FIGURE!

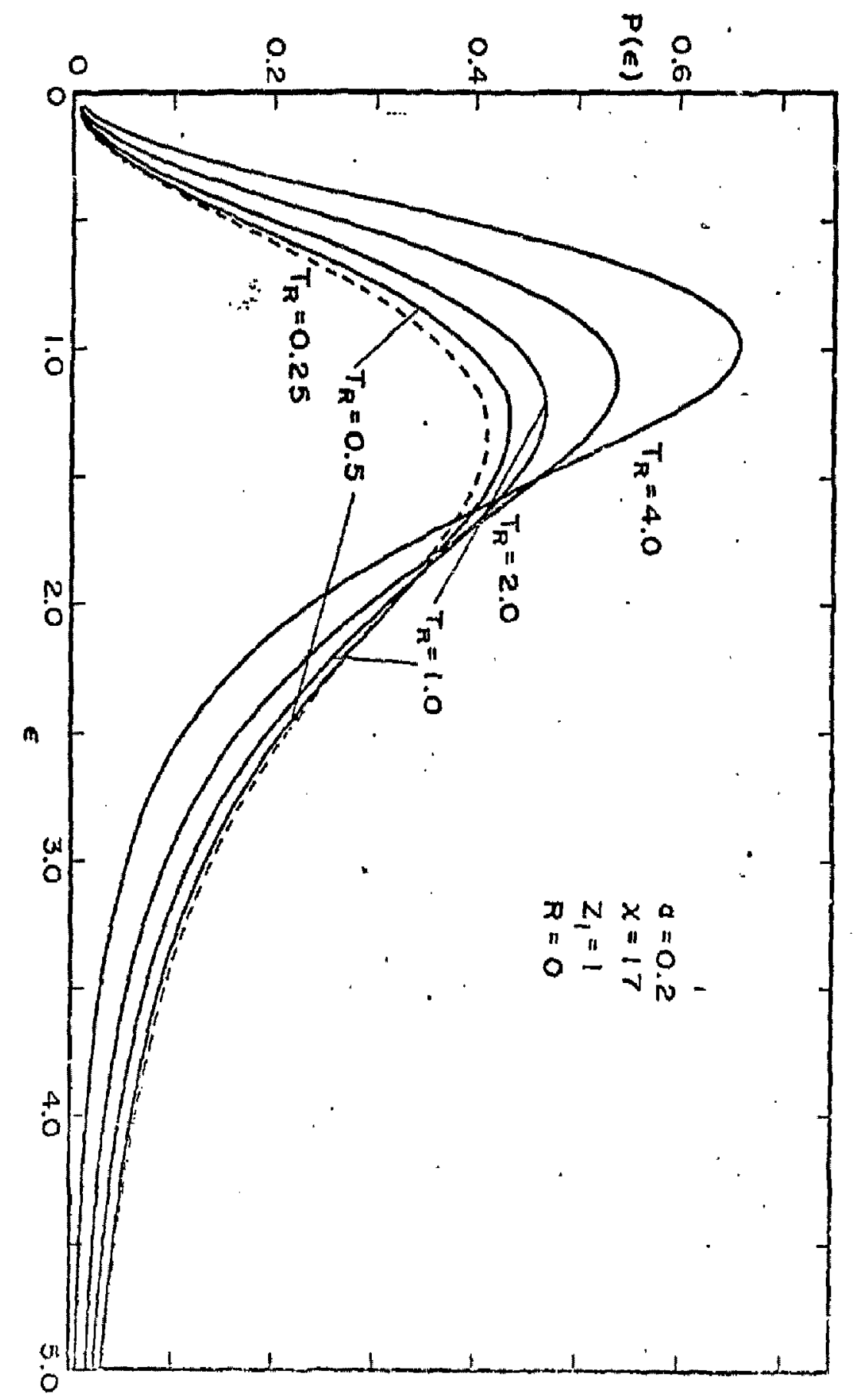


FIGURE 2

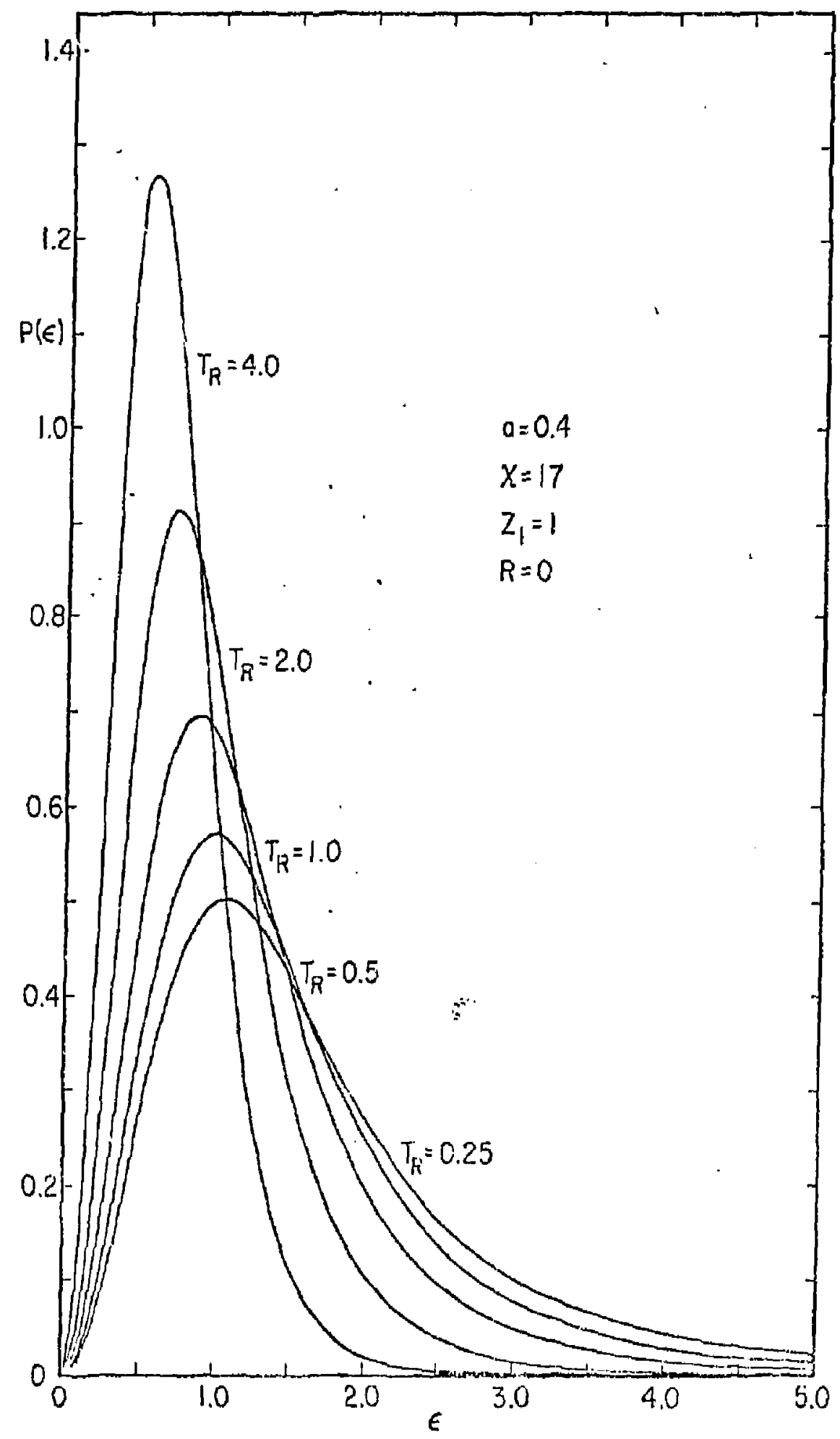


PIGURE 3

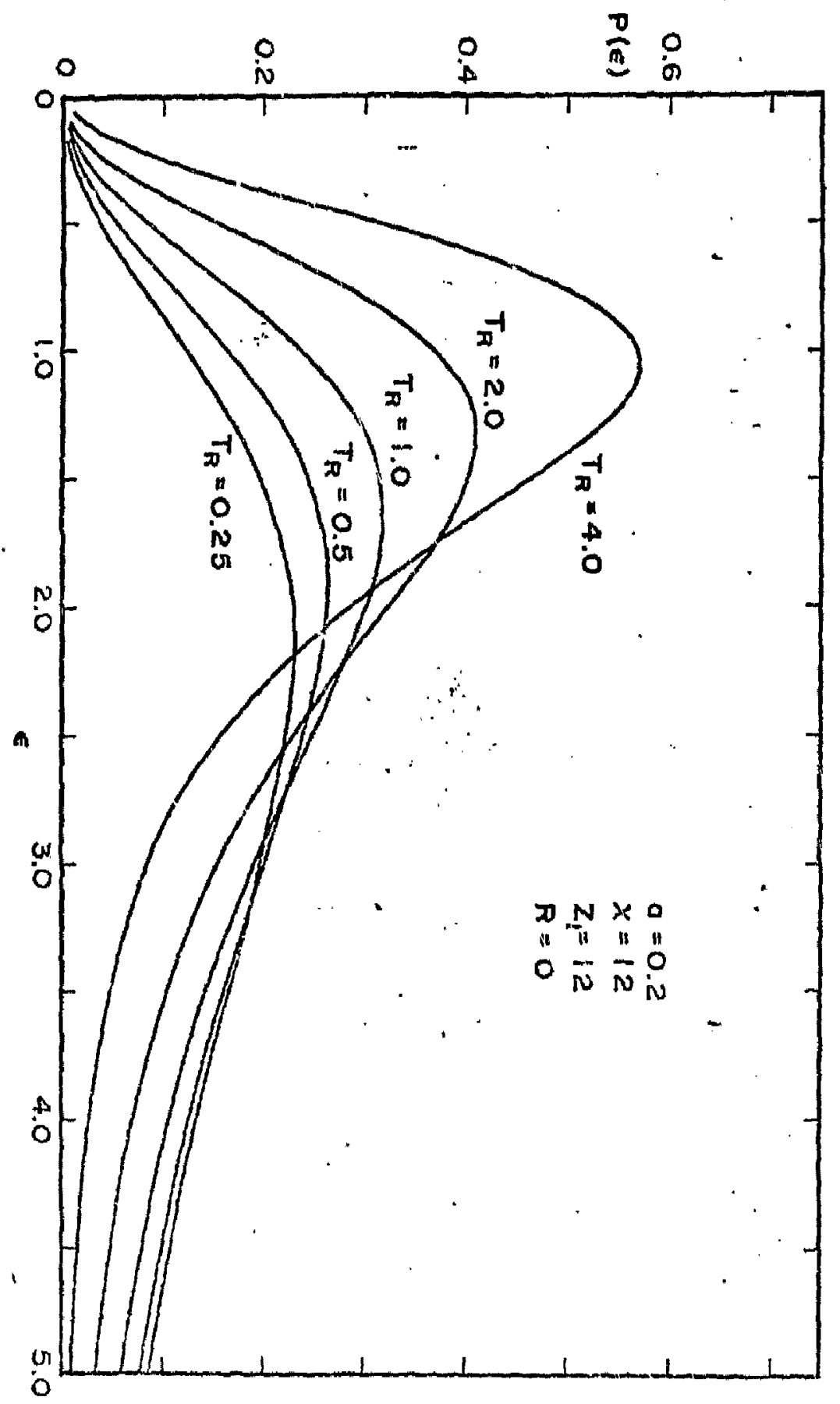


FIGURE 4

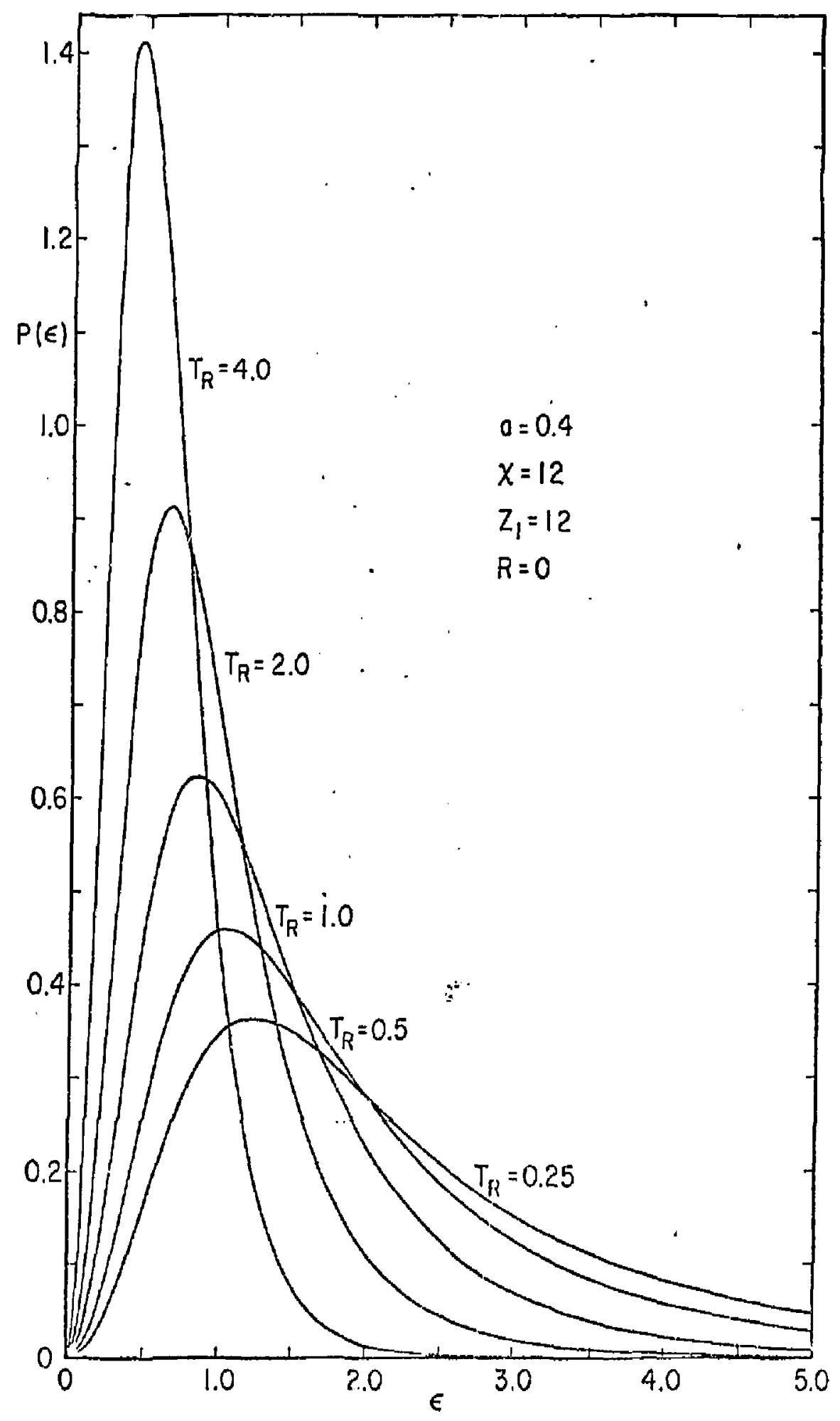




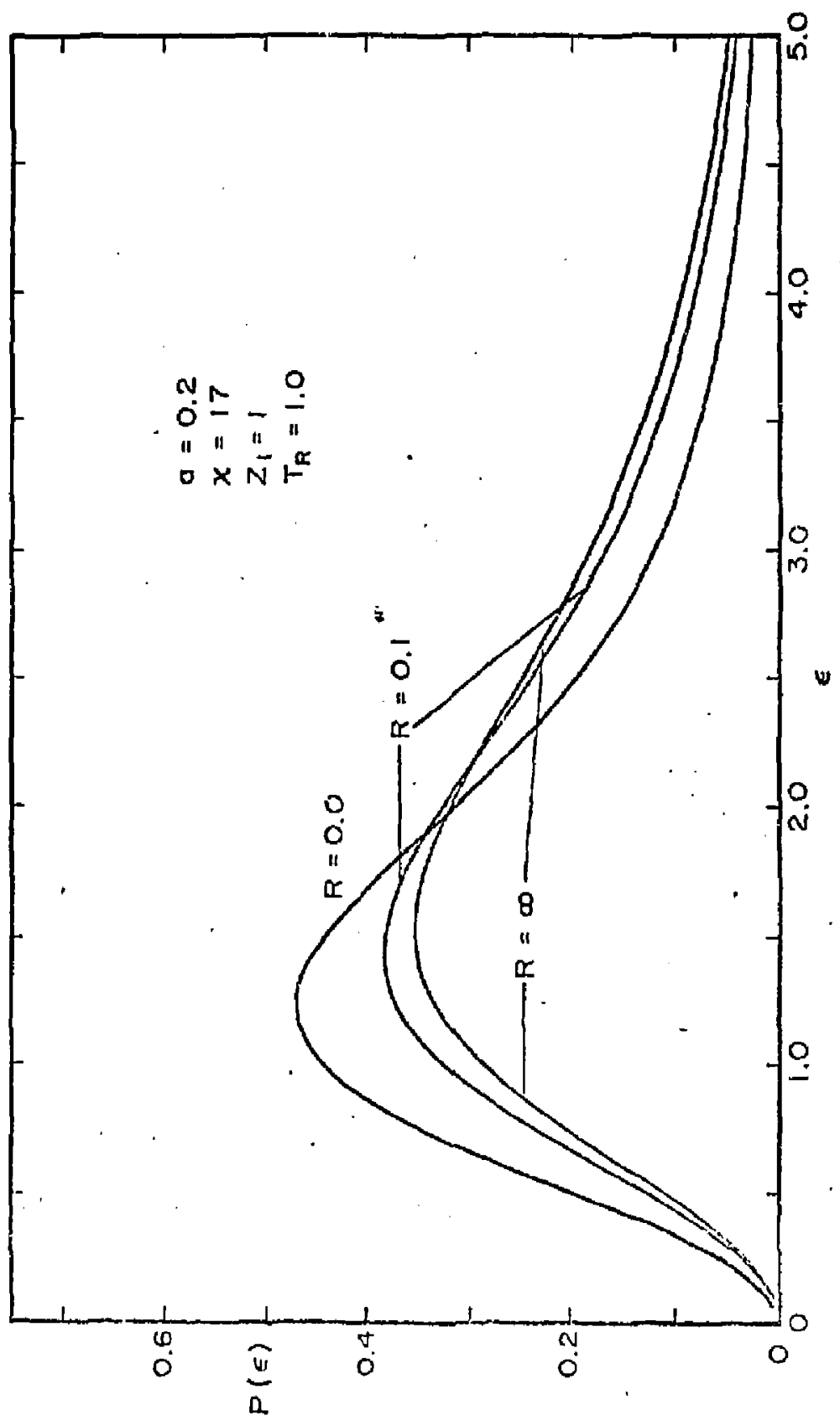


FIGIRE 6

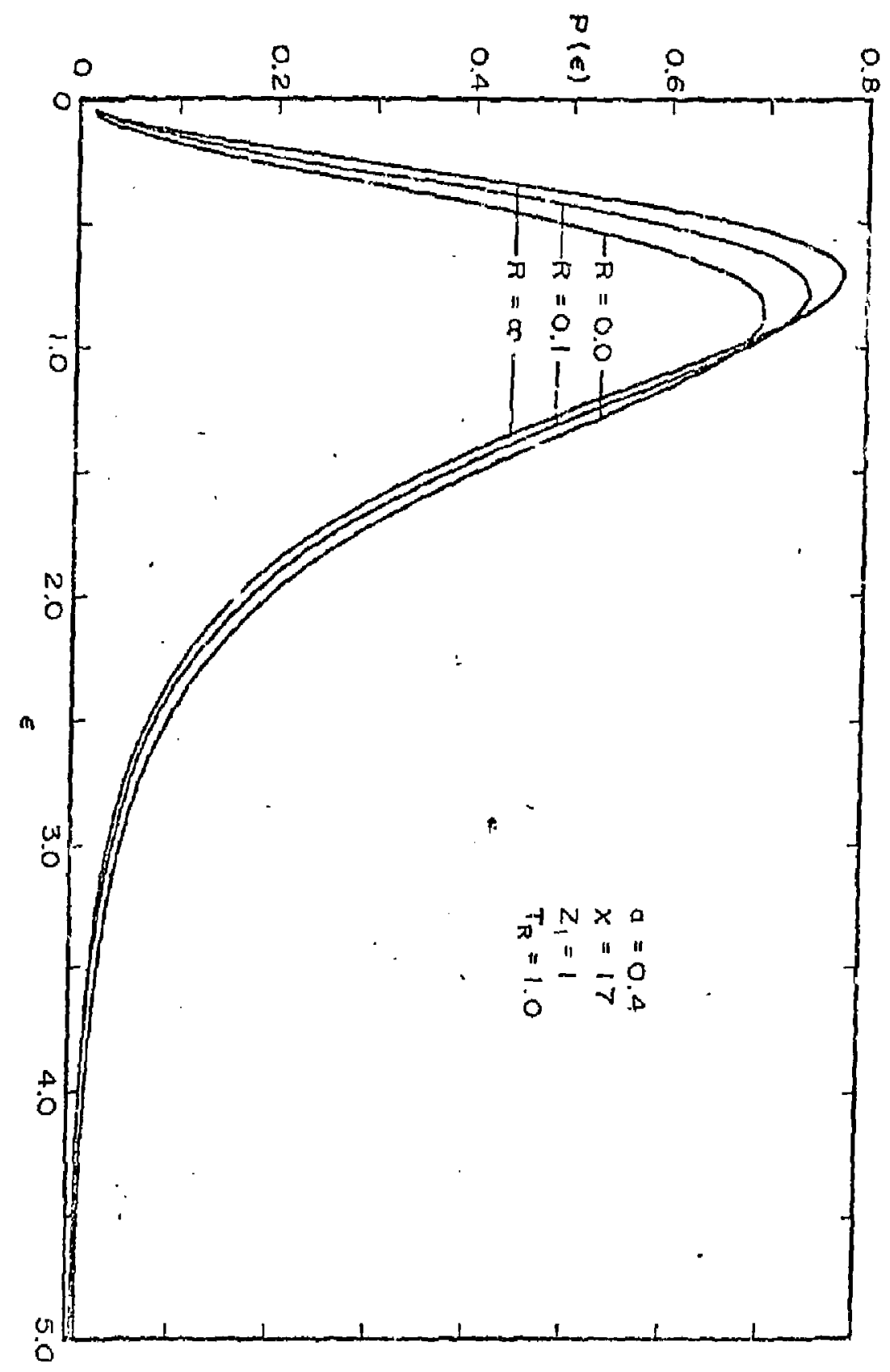


FIGUR: 6

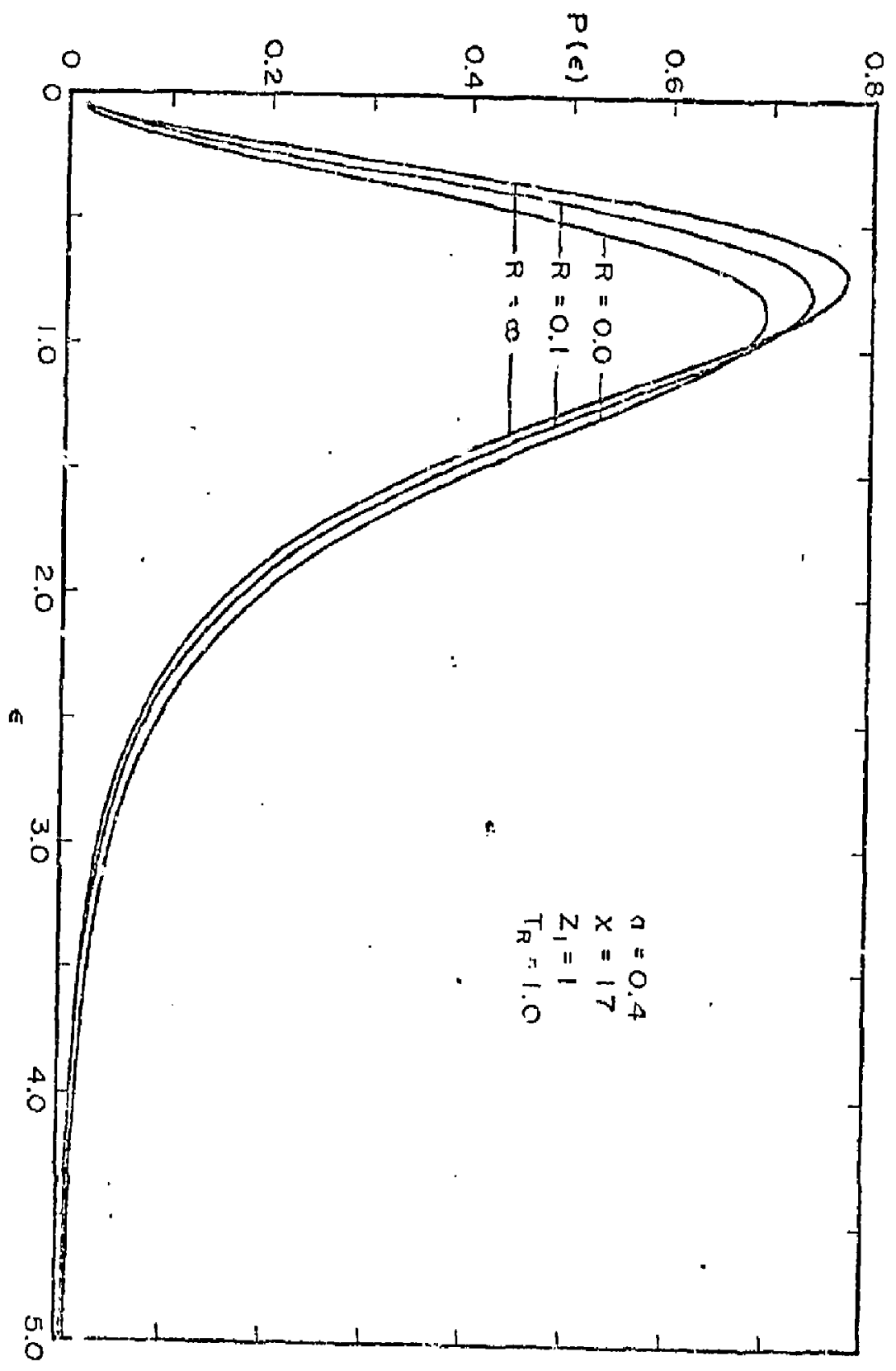

